salicylate of soda cannot be given in such dose without some risk. Salicin may thus be given without fear.

The practical issue with which we have to deal is thus a very narrow one. Given two remedies which cure acute rheumatism with equal certainty and equal speed, but which, independently of their anti-rheumatic effect, exercise different actions on the system, which shall we prefer-that which has a tonic, or that which has a depressing action?that which gives rise to no unpleasant effects, or that which may cause alarming, possibly fatal, depression? It may, indeed, be said that such large doses are not necessary. My answer is, that to get the full beneficial effects of either salicin or salicylic acid in acute rheumatism, such large doses are necessary. By smaller doses-ten or fifteen grains every hour or every two hours-an attack of acute rheumatism may be arrested in two or three days. But let the remedy be given in the larger dose, and the process of the disease may be arrested in half the time. In a malady which tends to involve the heart and entail on the patient the terrible results of an endocarditis, every hour is of consequence. Cut the malady short in one day, and you may ward off cardiac complications which may appear if it lasts for two or three. It takes about an ounce of salicin or of salicylic acid to cure a case of acute rheumatism. The sooner this quantity is got into, or rather is passed through, the system the better. My practice now is to give thirty grains every hour. $B y$ the time that an ounce has been thus taken-that is, in sixteen hoursthe patient is generally free from pain, and the temperature at or near the normal. I then give thirty grains every two or three hours till another ounce is consumed. After that thirty grains are given three times a day for a week or ten days, to guard against the possibility of relapse. Not unfrequently the patient feels better after three or four powders have been taken, and is practically out of the attack before the ounce is consumed. In such cases the interval between the doses may be widened after six or eight have been taken. Such is the course of events in favourable cases, and almost invariably their course in young subjects who have not previously suffered, or have done so only once or twice. In older subjects, who have had frequent and long-continued attacks, the acute symptoms may be as speedily allayed, but convalescence is more tardy and more apt to be interrupted. Cases treated by salicin seem to convalesce and pick up more quickly than those treated by salicylic acid or salicylate of soda.

Other of the salicyl compounds besides salicin and salicylic acid are available, and may prove of service. To only one of these would I now direct attention. Growing abundantly during the summer in our meadows, and by the sides of streams and ditches, is found the common meadow. sweet, the Spiræa ulmaria. The flowers of this plant contain a peculiar oil called oleum spiræ. This oil is salicylous acid. It is a slightly coloured mobile liquid. Taken alone or dissolved in spirit, it has a hot, pungent taste. Like salicylic acid, it causes some irritation of the throat when swallowed. From the few observations which $I$ have made, I am disposed to think that an infusion of the flowers of the meadow-sweet may prove a serviceable remedy in rheumatism. As the plant will soon be in flower, I throw out the suggestion now in the hope that those who have the opportunity to do so may test its efficacy.

Cadogan-place, Belgrave-square.

\section{NOTES ON A}

\section{CASE OF STRICTURE OF THE URETHRA, FOLLOWED BY RUPTURE.}

TREATMIENT BY PERINEAL SECTION, AND SUBSEQUENTLY BY FORCIBLE DILATATION.

By Surgeon-Major R. N. MACPHERSON, ARMY MEDICAL DEPARTMENT.

Privite J. Cease in China in 1869, while serving there with his regiment, and since then he suffered more or less from it, having been several times in hospital undergoing treatment.

On March 2nd, 1879, he was admitted to hospital complaining of retention. On passing an instrument (No. 4 size) down the urethra, it was found that three different strictures existed-namely, one an inch from the orifice, one half an inch further down, and one about an inch beyond that, through which it was impossible to pass No. 2 catheter. On March 4th No. 5 was passed through the two anterior strictures, but nothing could be passed through the third one.

On the morning of March 5th, while straining a little at micturition, he felt something suddenly give way, and this was followed immediately by rapid infiltration of urine into the cellular tissue of the penis, which soon became of enormous size, distended, and of dark colour, with highly urinous odour. There was no infiltration into the tissues of scrotum or perineum. The patient was seen an hour after the rupture took place, and free incisions were at once made into the tissues of the penis, by which means a large quantity of urine was allowed to escape and drain away, and the more urgent symptoms for the time were relieved. At 1 P.M., after consultation with Dr. Orr, civil surgeon, it was decided to cut down in the middle line of the perineum so as to permit the urine to escape from the tissues and endeavour to pass a catheter into the bladder. Previous to operating, the patient was placed in the lithotomy position, and chloroform administered, but as it was found impossible to get the patient under the influence of the drug, the attempt was abandoned, and the operation proceeded with as follows:-An incision was made in the middle line of the perineum, commencing half an inch in front of the anus, and carried upwards towards the scrotum, this incision being about an inch in depth. It was now tried to pass a catheter down the urethra to the seat of the incision, but this being found impossible, a No. 8 catheter was introduced into the bladder through the incision in the perineum, and tied in with tapes. The incision was accompanied by a considerable amount of hæmorrhage, and by free flow of urine, by which the swelling of the penis was much reduced. Patient was now placed in bed, and an opiate administered.

March 6th.-Feels easy this morning, and passed a good night ; penis much swollen still ; urine comes freely through the catheter, and is rather bloody. There being a very offensive and urinous smell, ordered charcoal poultice to penis, and carbolic lotion to be sprinkled over the bedding, \&c.

8th.-Catheter removed and fresh one introduced into the bladder by perineum; penis much swollen and sloughing; patient's strength keeping up well. Ordered two grains of quinine twice daily, and to have wine, brandy, beef-tea, eggs, \&c., every day.

1lth.-Penis still much swollen and sloughing; glans penis denuded of skin by large circular eroding slough, which suppurates freely; wound in perineum looks healthy, and is kept clean by means of carbolic lotion and poultices at times.

12th.-Going on favourably; sloughs look healthy; urine comes away freely by the catheter in perineum. Continue.

15th. - Slough and wound in perineum look healthy.

21st.-No. 2 gum elastic catheter was passed down the urethra as far as the incision in perineum, and retained two hours.

24th.-No. 4 was to-day passed down in the same manner, and retained two hours.

26th. - Passed No. 4 again; swelling of penis much diminished, and looking healthy.

28th. - This morning Holt's dilator, largest size, was introduced as far as the incision in perineum, and all the strictures ruptured. This operation was followed by slight pain and shock.

29th.-This morning No. 8 catheter was withdrawn from the bladder by perineum, and introduced through the urethra into the bladder, and tied in with tape.

30th.-This morning the patient feels quite easy, and the catheter left in bladder gives rise to no sensation of discomfort. Wound in perineum looks healthy, as well as penis. Slough diminishing in size, and healing.

April 1st.-On withdrawing the catheter he can pass his urine, but has a little pain and scalding, and some of it escapes by an opening at the side of the penis, and a little by the perineum. No. 8 catheter is passed occasionally.

10th. - Catheter not required now. Can pass his urine in a large stream, and has no pain or scalding. A little still comes away by the perineum. Penis of almost natural size. Slough almost healed.

On the 15 th he was up and walking about, and felt better 
than he had done for the last ten years. Urine came away in large stream, and gave him no trouble. On the 18th he was convalescent.

Fleetwood, Lancashire.

\section{NOTES ON THE TREATMENT OF SKIN DISEASES.}

BY J. B. BRADBURY, M.D.,

PHYSTCIAN TO ADDENBROOKE'S hOSPITAL, CAMBRIDGE, ETC.

\section{II.-THE TREATMENT OF ECZEMA.}

THERE are few diseases which reward the physician more for his attentive study and careful treatment than eczema. The disease assumes so many forms, each of which requires some modification of treatment, that persons whose opportunities of seeing the disease are somewhat limited often fail to cure it. Hence patients seek the advice of a specialist. Cases of acute eczema speedily recover if the patients are placed upon an unstimulating diet, and have soothing applications to the skin. In acute general eczema the alkaline and bran baths are very valuable, and local applications of olive-oil and lime-water (the Linimentum calcis of the Pharmacopceia), or lead lotion. When the disease has sumewhat subsided, the internal administration of arsenic and the local application of zinc ointment hasten the cure. In the case of a gentleman I saw in consultation, who was trity and had albuminuria, colehicum with magnesia quickly retioved the malady. These remedies are also very valuable in chrouic eczema occurring in persons of a gouty habit. Inated, in eczema, as in all diseases, the importance of looking fur some diathesis cannot be over-estimated. A disease often resists cure till such constitutional vice has been discovered and corrected. A short time ago I cured a gentleman of souty eczema with liquor potassæ in thirty-minim doses, given with compound infusion of gentian three times a day. In chronic eczema of the hands arsenic almost invariably does good, and, as a local application, the diluted nitrate- ofwercury ointment. For eczema of the axillæ, which is frequently accompanied by boils, the internal administration of the perchloride of mercury, and the local application of mercurial ointment, are almost a specific. I have cured two cases xf this kind which had resisted all other treatment. The combintation of iron with sulphate of magnesia is most valuable in the treatment of eczema in anæmic young women with cunstipated bowels. The dose of sulphate of iron should be larger than that usually given. I give three- or four-grain cuses. In anzemic young men the tincture of perchloride of iron, in at least half-drachm doses, answers better than the sulphate. I quickly cured a medical student of chronic tezema of the legs by this treatment, when other remedies prescribed by a specialist had failed. In chronic eczema of the face an ointment of equal parts of white precipitate witment and either zinc or cermpound subacetate-of-lead u.ntment is very useful. Sometimes, especially where the liuiry parts are affected, the dilute nitrate-of-mercury ointinent succeeds better. In eczema of the lips a private patient has derived great benefit from an ointment composed of almond oil, yellow bees'-wax, new honey, and oxide of zinc-a formula which $\mathrm{I}$ obtained from a paper by Dr. Durkee in the Jourral of Cutaneous Medicine. I have cured two cases of eczema of the nostrils by the application of dilute nitrate-of-mercury ointment. This ointment is best uiluted with vaseline. Preparations of tar are of great use in some cases of chronic local eczema, but English skins ane not so tolerant of these remedies as German skins.

Patients subject to chronic eczema should, as a rule, avoid salt meats, soups, sweets, acids, fruits, pastry, and raw vegetables.

Eczema in young children is frequently a very troublesone malady, probably owing to the disturbing influence of cicutition. In chiluren a few months old, where the disease is syphilitic, I give grey powder night and morning, and apply a mercurial ointment. When the disease has somevinit subsided, $I$ give the syrup of the iodide of iron. The perchloride of mercury has disappointed me in these cases. In rou-syphilitic eczema, after correcting any error in diet ard attending to the state of the secretions, I prescribe the ferturacuicul mixtule of Mr. Erasmus Wilson and apply the zinc ointment, and generally with the happiest results. I have recently cured three cases of eczema of long standing, which had resisted all previous treatment, by this method. It is very important in this, as in all forms of eczema, that the treatment should extend over a considerable time, in some cases six months. In eczema of the scalp, and generally in impetiginous eczema, after the removal of the scabs by poultices and oil, the local application of the unguentum hydrargyri cum plumbo of the Skin Hospital is invaluable. Eczematous children are almost invariably benefited by cod-liver oil.

\section{CASE OF}

\section{IMMEDIATE CURE OF SUICIDAL MANIA BY THE INDUCTION OF PREMATURE LABOUR; WITH REMARKS.}

BY J. THORBURN, M.D., M.R.C.P., PROFESSOR OF OBSTETRIC MEDICINE, OWENS COLLEGE, MANCHESTER; OBSTETRIC PHYSICIAN TO THE MANCHESTER ROYAL INFIRMARY.

ON January 29th, 1879, I was asked by Dr. Heckscher, of Manchester, to see with him, in consultation, a case of very considerable interest, the particulars of which I give with his kind permission.

Mrs. W-, aged thirty-two, was in the twelfth or thirteenth week of pregnancy. She had formerly had four children and two miscarriages, and had on each occasion suffered much from the usual sympathetic affections of preg. nancy. During the two preceding ones she had been much troubled with morbid sensations 'and ideas, bat had reso. lutely held them in control, and had acquiesced in all measures calculated to remove morbid associations of ideas or to maintain the balance of the physical functions. From the commencement of pregnancy this time she became possessed with the idea that death would be a necessary consequence of it-not, of course a very uncommon presentiment. Constantly recurring sickness, dyspepsia, and anorexia rapidly deepened the impression, and within a very short time determination to accomplish her own predictions took possession of her, necessitating constant vigilance on the part of her friends. She was not so much emaciated as night have been expected ; originally a very strong woman, she might still be considered in fair condition; and the induction of early abortion on the usual grounds was out of the question. Her manner, the expression of her eye, and her taciturn suspicious mode of answering questions, were such as one rarely sees outside of an asylum. I agreed with Dr. Heckscher that if improvement did not speedily take place, from the injection of chloral per rectum and other measures which we tried, the induction of labour would be fully justified, although I was unaware of many, if any, precedents to guide us.

On Feb. 27th we accordingly introduced a flexible bougie into the uterus at 9.30 A.M., and left it there. Dr. Heck. scher saw her in the evening, and found that all sickness had ceased. There was a little sanguineous discharge. She expressed herself now as perfectly well and happy, and even desirous that pregnancy might go on to the full term. $\mathrm{He}$ withdrew the bongie. Next day all the symptoms, mental and bodily, had returned in full force; and, as no actual labour pains had set in, the bougie was once more introduced. Labour supervened during the night, and a fotus, of apparently about sixteen weeks, was expelled, with its secundines quite entire. From this moment every morbid psychological symptom disappeared, together with vomiting, dyspepsia, \&c. The patient become immediately sane, recovered with out a symptom, and is now in the enjoyment of perfect health.

Iccmciks. - Several interesting questions are suggested by this case, and, without professing to have made any very careful search into the literature of the subject, there are, I am sure, very few recorded cases affording a satisfactory answer to them. ${ }^{1}$

Was the induction of labour before the viable period

I In No. 3 of vol. i. of "Brain" Dr. Savage relates a case of insanity cured by uterine replacement, and in the Brit. Med. Journal of Apri 1 ?th, 1879 , Dr. Bind publishes a case similar to the present one, excel thit labour was not induced till after the viable age. 